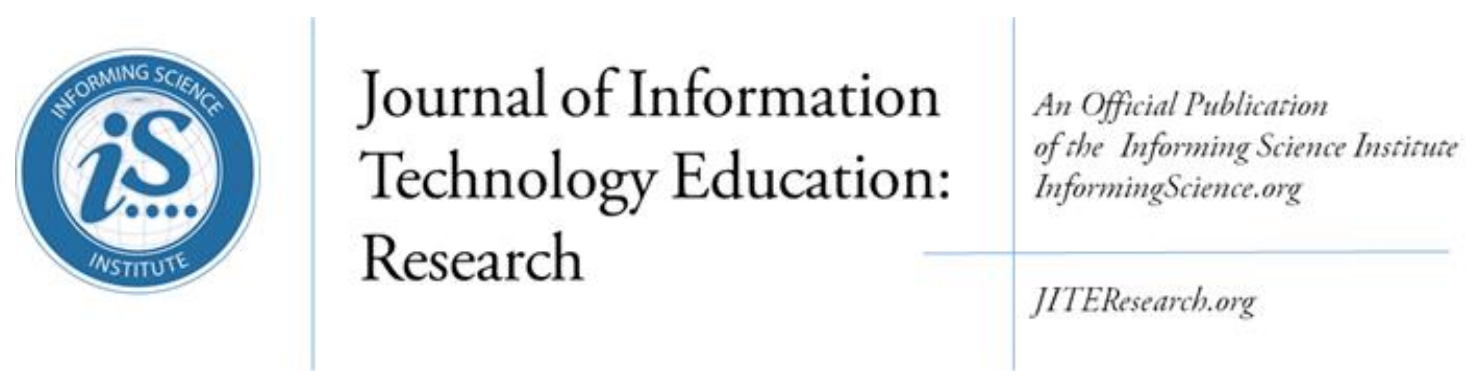

Volume 19, 2020

\title{
COVID-19 AND IT EDUCATION: INTRODUCTION TO THE SPECIAL SERIES
}

\author{
Christopher Cheong* \\ Jo Coldwell-Neilson
}

Tian Luo

Kathryn MacCallum
RMIT University, Melbourne, Australia

Deakin University, Geelong, Australia

Old Dominion University, Norfolk, VA, USA

Canterbury University, Christchurch, New Zealand christopher.cheong@,rmit.edu.au

jo.neilson@deakin.edu.au

tluo@odu.edu

Kathryn.MacCallum@,canterbury.ac.nz

*Corresponding author

\section{COVID-19 AND EDUCATION}

The COVID-19 pandemic quickly and suddenly affected many, if not all, parts of the world. As the pandemic progressed, it became evident that it would not be a situation that could be resolved in the short-term as many people believed or hoped. The pandemic, and the subsequent social restrictions that governments have enacted to restrain its spread, has permeated into almost every aspect of our lives.

From an educational perspective, educators and students managed the social restrictions by transitioning to teaching and learning completely online. While teaching and learning online is not new, the rapid transition from face-to-face to online resulted in an approach that is now known as "Emergency Remote Teaching" (Hodges et al., 2020). Some key differences are that the teachers who shifted their teaching online did not have adequate time to purposefully design their courses for online delivery. Furthermore, they did not necessarily have the training and experience of fully online teaching. Similarly, students who were used to engaging with learning in a face-to-face or blended learning environment were suddenly forced into using only the online medium for their studies. All of this, in the midst of a pandemic affecting both the teachers and students, as well as their family, friends and their broader communities.

In such times of crises, it is important for education to continue as it plays a myriad of roles for those involved or impacted by the crises. Most importantly, education also provides knowledge and skills to survive crises. In the short-term, it can be both life-saving and life-sustaining as it provides a way for affected individuals to be identified and supported. From a psychosocial perspective, education

Cite as: Cheong, C., Coldwell-Neilson, J., Luo, T, \& MacCallum, K. (2020). COVID-19 and IT education: Introduction to the special series. Journal of Information Technology Education: Research, 19, 725-729. https://doi.org/10.28945/4654

(CC BY-NC 4.0) This article is licensed to you under a Creative Commons Attribution-NonCommercial 4.0 International License. When you copy and redistribute this paper in full or in part, you need to provide proper attribution to it to ensure that others can later locate this work (and to ensure that others do not accuse you of plagiarism). You may (and we encourage you to) adapt, remix, transform, and build upon the material for any non-commercial purposes. This license does not permit you to use this material for commercial purposes. 
provides a sense of normalcy, stability, structure, and hope for the future. In the long-term, it provides the necessary building blocks for economic recovery and stability (Inter-Agency Network for Education in Emergencies, 2004).

As the pandemic is still unfolding as this series is being published, the full effects of COVID-19 on education will not be known for quite some time. However, this Special Series focuses on how educators and students managed the initial shift to teaching and learning to fully online. It provides early research articles on the impact of the pandemic on education, the lessons learnt, and how these lessons can be applied to improve learning during and after pandemics and other crises.

\section{LEARning ANd Teaching DURINg THE PANDEMIC}

As educators and students are two important stakeholders in education, the Special Series contains four articles that focus on these two perspectives. The series begins by examining the factors that affect the quality of e-learning during the pandemic (Elumalai et al., 2020). This study surveyed 784 undergraduate students from higher education institutions in India and the Kingdom of Saudi Arabia. Using a structural equation modelling (SEM) approach, this study revealed that the seven factors under study (i.e., administrative support, course content, course design, instructor characteristics, learner characteristics, social support, and technical support) positively affected the quality of e-learning. Given that students' perceptions varied significantly depending on gender, course level, and the quality of e-learning, a practical recommendation is for e-learning offerings to be tailored based on gender and course level.

A significant issue in delivering teaching online is to ensure the quality and integrity of assessments. This can be a significant challenge for academics who are not experienced with online learning and teaching. The second article in the series investigates the preparedness of higher education institutions for online assessments during COVID-19 (Sharadgah \& Sa'di, 2020). The research surveyed 96 academics from Prince Sattam bin Abdulaziz University in Saudi Arabia to determine their perceptions regarding the preparedness of Institutions of Higher Education (IHE) for online assessment. The findings raised concerns that higher education institutions were not completely prepared for proper online assessments and required for more robust and effective mechanisms to assess online work, especially regarding formative assessment such as examinations. The study highlighted the need for more stringent mechanisms around ensuring academic integrity for online assessment and proposes a number of practical recommendations, focused on technology, training and policy, to support more effective practice within the IHE context.

Teachers from different levels of education experienced teaching online during the pandemic in different ways. The third article in the series uses multiple case analysis to provide an account of the lived experiences of three Hong Kong educators, from primary, secondary, and tertiary institutions (Ng et al., 2020). The study demonstrated findings collectively across three case studies, suggesting teachers' prominent role in driving a blended learning pedagogical approach. This blended learning model, which combines the advantages of asynchronous and synchronous learning, is deemed desirable especially during emergency remote teaching, as it enables students to be flexible and autonomous, as well as provides them with opportunities for social interactions.

The final article in the series focuses on an exploration of how language teachers engaged with teaching online in Indonesia (Lie et al., 2020). This in-depth case study collected data using an online survey, weekly reflections, and interviews with 18 teachers from four regions in Indonesia. Group interviews with five of each of the teachers' students were also conducted. The study found five interrelated factors within the online learning process that affected five levels of engagement, including learners' access to technology, teachers' prior exposure to online learning, teachers' technological knowledge and pedagogical knowledge, as well as the support system for teachers. The study's rec- 
ommendations encapsulate the importance of the Indonesian government's role in ensuring the provision of technology infrastructure and devices, while highlighting the necessity of teachers' active participation in ongoing professional development that centers on student-centered pedagogy.

\section{CONCLUSION}

As we are still in the midst of the pandemic at the time of the publication of this series, the research presented herein sets the scene and discusses some of the early impacts of COVID-19 on education and some of the ways educators have sought to address these issues.

Although the pandemic has affected the global population, destroyed livelihoods, and resulted in many deaths, it has had a catalysis effect on global technology adoption. Humanity has shown a united resilience by not only searching for a vaccine and employing a variety of measures to limit the spread of COVID-19 but by finding ways to leverage our existing technologies and continue to innovate to enhance our quality of life - the raison d'etre for research.

From a technological (including IT Education) perspective, the silver lining is the rapid adoption of technology on a global scale in many aspects of our lives. The speed and the widespread adoption of technology during the pandemic is unparalleled. This is a phenomenon worthy of further in-depth study for the benefit of humankind, so that we are better positioned to understand such crises, how to manage them, and how to thrive post-crisis.

\section{ACKNOWLEDGEMENTS}

We are indebted to the editors and reviewers of the articles in the Special Series, without whom this publication would not have been possible. While managing their heavier-than-usual workloads, and dealing with the stress and anxiety that the pandemic brings, they have ensured a rigorous review of the articles in the series.

We would like to acknowledge our hardworking editors, Dr Man Fung (Kelvin) Lo, Dr France Cheong, Dr Krassie Petrova, and Dr Donna Jean Satterlee, who managed the review process for the articles in the series, and the reviewers who provided their views on how the articles could be improved.

\section{REFERENCES}

Elumalai, K. V., Sankar, J. P., R, K., John, J. A., Menon, N., Alqahtani, M. S. M., \& Abumelha, M. A. (2020). Factors affecting the quality of e-learning during the COVID-19 pandemic from the perspective of higher education students. Journal of Information Technology Education: Research, 19, 731-753. https://doi.org/10.28945/4628

Hodges, C., Moore, S., Lockee, B., Trust, T., \& Bond, A. (2020). The difference between emergency remote teaching and online learning. Educause Review, 27. https://er.educause.edu/articles/2020/3/the-differencebetween-emergency-remote-teaching-and-online-learning

Inter-Agency Network for Education in Emergencies. (2004). Minimum standards for education in emergencies, chronic crises and early reconstruction: UNESCO.

https://hivhealthclearinghouse.unesco.org/library/documents/minimum-standards-educationemergencies-chronic-crisis-and-early-reconstruction

Lie, A., Tamah, S. M., Gozali, I., Triwidayati, K. R., Utami, T. S. D., \& Jemadi, F. (2020). Secondary school language teachers' online learning engagement during the COVID-19 pandemic in Indonesia. Journal of Information Technology Education: Research, 19, 803-832. https://doi.org/10.28945/4626

Ng, D. T. K., Reynolds, R., Chan, H. M. Y., Li, X. H., \& Chu, S. K. W. (2020). Business (teaching) as usual amid the COVID-19 pandemic: A case study of online teaching practice in Hong Kong. Journal of Information Technology Education: Research, 19, 775-802. https://doi.org/10.28945/4620 
Sharadgah, T. A., \& Sa'di, R. A. (2020). Preparedness of institutions of higher education for assessment in virtual learning environments during the Covid-19 lockdown: Evidence of bona fide challenges and pragmatic solutions. Journal of Information Technology Education: Research, 19, 755-774.

https://doi.org/10.28945/4615

\section{BIOGRAPHIES}

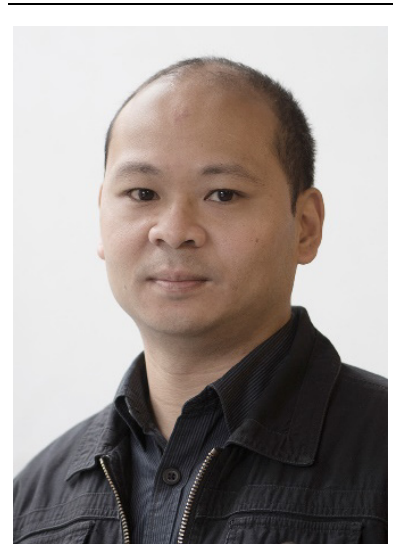

Christopher Cheong is an Associate Professor in the Department of Information Systems and Business Analytics at RMIT University. He has an academic background in Computer Science and his research focuses on the use of technology to enhance learning. In recognition of his teaching excellence and technology-enhanced learning research, he was awarded an Office of Learning and Teaching Citation for Outstanding Contributions to Student Learning in 2016 and became a Fellow of the Higher Education Academy in 2018.

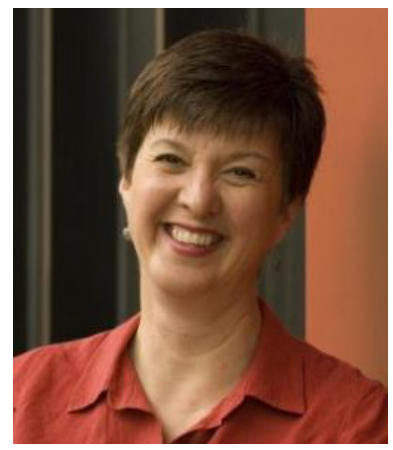

Jo Coldwell-Neilson has been an academic for 30 years. She has built a strong research and teaching profile engaging students in and with technology. She has been active in a variety of projects including implementing educational technologies in her teaching and in the teaching and learning activities at Faculty and University levels. Jo's research includes investigations into gender issues in IT, digital technology uptake in schools and higher education, and preparing students for careers in a digital environment. In 2016 Jo was awarded an Australian Learning and Teaching Fellowship. Jo is currently Associate Dean (Teaching and Learning) in the Faculty of Science Engineering and Built Environment.

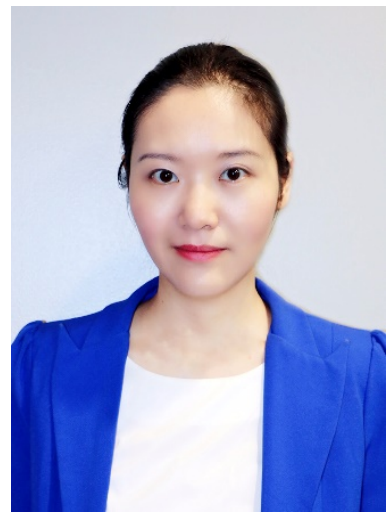

Tian Luo is an Associate Professor of Instructional Design and Technology at Old Dominion University, USA. She earned her Ph.D. in Instructional Technology from Ohio University. Formerly, she worked as an instructional design professional in both higher education and corporate settings. Her research interests center on teaching and learning with and through social technologies and media, as well as designing social mediasupported learning environments. Her broader research interests include instructional design, mobile learning, gamification, open educational resources, and learning analytics. 


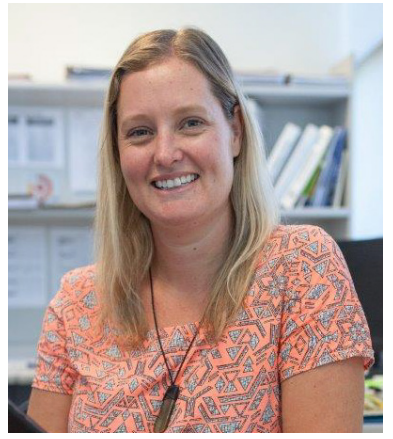

Kathryn MacCallum is an Associate Professor of Digital Education Futures within the School of Educational Studies and Leadership at the University of Canterbury (UC), NZ. She is also the Director of the Digital Education Research Lab (DeFL) at UC which focused on research the effective integration of digital technology into education. Prior to her role at UC, Kathryn was an Associate Professor of Computing at Eastern Institute of Technology, Napier, New Zealand. Kathryn's research has centered on exploring how technology can be effectively used to support teaching and learning and has authored over 40 research conferences papers, journal articles, book chapters, and edited books on this topic.

Kathryn has also been involved in a number of research projects, both in New Zealand and internationally, exploring innovative approaches to the integration of technology within all sectors of education. She also serves as Editor in Chief for a number of international journals focusing on education technology and is a current serving as an executive member for the International Association for Mobile Learning (IAmLearn). 